\title{
Should I Stay or Should I Go? Engaging and Disengaging Experiences in Welfare-Sector Volunteering
}

\author{
Andreas $\operatorname{Kewes}^{1}$ (D) Chantal Munsch ${ }^{1}$
}

Published online: 1 May 2019

(C) The Author(s) 2019

\begin{abstract}
This paper seeks to reconstruct the specific experiences that strengthen or erode the commitment of volunteers in the welfare sector. The empirical basis is narrative interviews with volunteers who have withdrawn from their role at a welfare organisation in Germany. The findings show tensions: on the one hand, experiences of successful relationships with clients and fellow volunteers strengthen volunteers' commitment. On the other hand, volunteers observe practices and approaches that run counter to their values. This tension between engaging and disengaging experiences arises from the welfare sector itself, for while care can enable close interpersonal experiences, it is also shaped by economisation. Overall, our study shows that the motivations underlying volunteers' long-term commitment can be both strengthened and undermined by actual volunteering experiences. In the light of our findings, we present heuristics for understanding volunteering processes that focus on field-specific experiences and tensions.
\end{abstract}

Keywords Care - Interviews - Protest - Resonance · Volunteering process

Andreas Kewes

andreas.kewes@uni-siegen.de

Chantal Munsch

chantal.munsch@uni-siegen.de

1 Department of Education and Psychology, University of Siegen, Adolf-Reichwein-Straße 2a, 57068 Siegen, Germany

\section{Introduction}

Research into access to and continuation in a volunteering role often focuses on the individual and his or her motives and resources. However, a number of research projects point to a need to understand volunteering as processual in nature and to consider each individual volunteer in the specific context of the given volunteering role (cf. HaskiLeventhal and Bargal 2008; O'Toole and Grey 2015; Willems et al. 2012). The research project presented below seeks to expand knowledge in this area and further develop a specific approach to processuality and tensions in volunteering contexts. The paper explores the specific dynamics of volunteering from the perspective of volunteers who have withdrawn from their roles at German welfare charities. Our analysis shows firstly that volunteers highlight very specific, typical experiences to give meaning to the development of their volunteering. It also reveals that the dynamics that lead to withdrawal arise from tensions: although the volunteers stress specific experiences that led to withdrawal, engaging experiences, experiences that strengthen their commitment, are equally important to an understanding of volunteering dynamics. Finally, both types of experience, the engaging and disengaging, are in our data closely connected to the field in which volunteering took place, namely the welfare sector. The aim of this paper is thus twofold. Firstly, it seeks to reconstruct those specific experiences that engage and disengage volunteers in the welfare sector. Secondly, it seeks to propose heuristics for understanding volunteering processes that end in withdrawal by focusing on field-specific tensions. The research paradigm is qualitative with this question of 
the reconstruction of social meaning, and the project uses narrative interviews.

The following pages begin by examining the current state of research into the processual and field-specific nature of volunteering (1) before setting out our research design (2), on which basis the study's findings are presented: firstly, the processual nature of volunteering and secondly the specific experiences that strengthen volunteers' commitment or distance them from their work. We then outline the tensions arising from those experiences (3) and finally, we focus on the role of the specific volunteering field (4). We conclude by summarising the key aspects of our research and placing them in the context of the current state of research.

\section{Volunteering as a Process Shaped by the Individual and Context: The State of Research}

Anyone calling for volunteering research to consider the context of volunteering is now preaching to the converted (cf. Snyder and Omoto 2008; Stukas et al. 2009). O'Toole and Grey (2015) argue that a comprehensive understanding of volunteering is only possible through research into the relation between individual and context. Their qualitative study reconstructs how the specific context of volunteering in a life-saving organisation shapes individual motivation. Of key relevance here are both the dangers of working on a boat and the need to save lives. At the same time, O'Toole and Grey show that various different aspects of volunteering, in particular emotions, social relationships and physical challenges, must all be considered. McAllum (2018) argues on the basis of qualitative interviews that understanding overall engagement with a volunteering role requires more than simply considering volunteers' personal, individual commitment. In her view, researchers must reconstruct the relationships that volunteers build with their clients (in McAllum's study refugees) and with the organisations in question. A quantitative study by Willems et al. (2012) confirms the significance of volunteering contexts to volunteering research. It shows that individual functional motives can explain the decision to start but not that to withdraw from volunteering. Willems et al. argue that explanations relating to volunteering in practice are more relevant, for example volunteers' actual interactions in their volunteering environment and overwork or stress experienced (ibid.: p. 897; cf. Dury 2018). This consideration of the links between individual motivations and the context of volunteering is central to the findings presented here and the underlying understanding of volunteering dynamics.
Exploring the dynamics of volunteering over time is also an important element of volunteering research. One of the most prominent models in this area is Omoto and Snyder's Volunteer Process Model (1995; Snyder and Omoto 2008), which divides volunteering into the three phases antecedents, experience and consequences. In a quantitative study of AIDS service volunteers, Omoto and Snyder (1995) found, for example, that helping dispositions (antecedents) correlated with satisfaction and integration into organisational processes during volunteering (experience) and that satisfaction in turn correlated with volunteering duration. It could therefore be concluded that volunteering duration depends not just on individual motivation but also on interpersonal experiences and experiences with the given organisation over the course of actual volunteering. On this point, Snyder and Omoto have also demonstrated that attitudes change as a result of volunteering in practice. Snyder and Omoto work with the functionalist paradigm in which people volunteer where volunteering is functional for them (for example generates satisfaction).

Chacón et al. (2007) seek to describe the volunteering process as a series of stages on the basis of a quantitative longitudinal study. They argue that the satisfaction of individual motives only explains why a volunteer remains at the start of volunteering and that the form of commitment changes in line with volunteering duration. Organisational commitment and the volunteer's role identity offer a better explanation of the subsequent course of volunteering.

While Omoto and Snyder and Chacon et al. describe volunteering dynamics from the standpoint of volunteering, Corrigall-Brown (2012) shows on the basis of a quantitative longitudinal study of participants in social movements that key moments in a participation trajectory such as persist, disengage and abeyance are also linked to turning points in the life of the individual (for example, ageing or changes in his or her paid employment) and not simply to factors inherent in that participation.

Haski-Leventhal and Bargal's (2008) ethnographic study allows them to describe more specifically the changes in the volunteering process. In a project about street work with at-risk young people, they show how volunteers go through five different phases (nominee, newcomer, emotional involvement, established volunteering and retiring). The volunteers' view of and knowledge about their volunteering and their emotional ties to the young people they work with, to the organisation and to their volunteering role overall change in each phase. HaskiLeventhal and Bargal describe four typical transitions (entrance, accommodation, affiliation and renewal) and two typical types of withdrawal (ejection and retirement; cf. Hustinx et al. 2010: p. 424). The qualitative approach 
allows an observation of specific moments of learning and negotiation in volunteering.

The role played in volunteering dynamics by experiences in specific volunteering contexts is demonstrated by Yanay and Yanay (2008) on the basis of a qualitative study of former volunteers who had worked with victims of violence in Israel. The volunteers felt unable to cope and, despite initial training, that their organisation provided little support. Those experiences led to their withdrawal. Such experiences are central to a decision not to start volunteering despite individual motivation and completed training. Key elements here were emotions such as fear and the feeling of being unable to cope. O'Toole and Grey (2015) also point to the significance of similar emotions. In their quantitative study of volunteers in a humanitarian non-profit organisation in the UK, Alfes et al. (2015) found that being able to experience how their volunteering work helped others led to volunteers wishing to remain in their role for longer or devote more time to it.

The research project presented below shows the relevance of such perspectives for volunteering research: it confirms that research must address the processual nature of volunteering. It clearly shows that the focus on an individual player with clear, rational motives must be broadened to consider a player in a given environment and set of circumstances. It illustrates the importance of the interaction between the individual volunteer and the context of volunteering. Both activities as a volunteer and the organisation in which volunteering takes place would appear relevant to that context. The qualitative studies in particular clearly demonstrate the significance of experiences and the emotions they involve. Growth and change in volunteers' knowledge over the course of their service, on the other hand, appears to be less well-explored in existing theory. ${ }^{1}$ We think that this knowledge of tasks, organisational contexts and interactions has an important role in the volunteer process, but is almost never explicitly discussed by former volunteers as part of their volunteering experience. It would therefore appear necessary to begin by defining this knowledge in a qualitative process that also explores how the underlying experiences can be placed in their social context. This approach requires a hermeneutic procedure, or more precisely a procedure based on the sociology of knowledge.

\footnotetext{
${ }^{1}$ In this paper, we do not use knowledge in the everyday sense of knowledge of something, but rather in the sense of knowledge (more precisely: volunteer knowledge) as employed in the sociology of knowledge, which also covers patterns of interpretation, emotions and perspectives.
}

\section{Sample and Research Method}

The empirical basis for the research project presented here is 18 narrative interviews with volunteers who have withdrawn from their volunteering roles at German charities. There are two reasons for this choice of approach. Firstly, the aim is to understand volunteering dynamics leading to withdrawal from the point of view of the volunteers. This means giving them the freedom to recount the story of their volunteering as experienced by them. We therefore avoided questions that set specific issues. Instead, we wanted the volunteers to raise those aspects of their story that they use to explain their departure. Secondly, narrative interviews provide an opportunity to record the entire volunteer process, in other words to present withdrawal in the context of other developments. Each interview started by asking interviewees to tell their story right from when they first began to consider volunteering to the volunteering itself and their departure, just as the situation had unfolded. Within this narrative, the interviewees were able to portray themselves in a way that made sense to them. For example, they could describe themselves as committed or critical. The interviews lasted between $30 \mathrm{~min}$ and $3 \mathrm{~h}$.

To allow a comparison with volunteers who had not dropped out, five group discussions were conducted with people who were still actively volunteering in charities. Group discussions were chosen in the light of the organisations to which the one-on-one interviews related. Each lasted approximately $1 \mathrm{~h}$. Only certain sections of this material were transcribed, unlike the interviews; we focused on passages with a particularly high level of interaction. The purpose of the group discussions was to record collective experiences. They acted as a control group to prevent only extreme cases being considered from among the experiences recounted in the narrative interviews. However, the group discussions contain less detailed narratives about engaging experiences than the narrative interviews and also present negative experiences as less hopeless. We believe both these aspects are a result of the context of data collection, which allows little scope for individual narratives. Indeed, that context is one in which participants can find mutual support in the case of negative experiences.

The sample covers a range of age groups, genders and immigrant backgrounds and a range of charities. Access to volunteers was obtained primarily through key figures at charities and at municipal volunteer centres. Volunteers were active in various different areas, for example in retirement homes, in language support projects, in support for victims of violence, and in mentoring and advisory services for migrants and the long-term unemployed. Most roles were intended to be for the long run. 
Passages were evaluated using the hermeneutic documentary method (cf. Nohl 2010). This method analyses not just what the volunteers say, but also and above all how they talk about their volunteering. In the project presented here, volunteers offered both effusive accounts of particularly "lovely" experiences and angry or critical narratives. A major focus in the evaluation is on all topics on which the respondents have expressed themselves with a particular passion or level of metaphor or in particular detail (Nohl 2012, p. 40). The documentary method is based on the premise that these "focussing metaphors" 2 [...] should be considered not least because that they can offer a correction to the topics selected by the researchers (ibid.). In our research project, such topics were primarily accounts of experiences that engage or disengage volunteers. A central aspect of this method is the comparison of passages from interviews with similar forms of narrative to uncover shared underlying experiences. To use the terminology of the documentary method, those shared experiences are documented in a similar, implicit way known as the pattern of orientation. In the project presented here, the search for a pattern of orientation meant the search for shared experiences that shaped volunteering dynamics up to the point of withdrawal. ${ }^{3}$ These experiences are set out below.

\section{The Dynamics of the Volunteer Process: Research Findings}

An analysis of the sequential nature of volunteer narratives shows firstly that volunteering must be understood as a process in which volunteers' knowledge about their service develops with their experiences. The volunteers do not recount their service as a single, fixed experience that has not changed or did not change. Instead, they give differing significance and meaning to individual tasks and experiences at different moments of the volunteer process. On the basis of an analysis of the narratives, we reconstructed

\footnotetext{
2 The term "focussing metaphors" in the documentary method refers to passages of a narrative characterised by a high level of interaction (as in group discussions) or in which (as in interviews) respondents express themselves with a particular focus and emphasis.

${ }^{3}$ When we were planning the research, our hypothesis on this point was that volunteers are most likely to drop out if they are labelled as "other", i.e. as people who do not fit into what is presented as the fixed and established environment of the organisation. We therefore initially primarily interviewed people with immigrant backgrounds who (had) volunteered in German charities. These organisations are described as traditionally deeply rooted in a particular social milieu and have traditionally seen people with an immigrant background above all in the role of clients. However, as we will see below, the narratives did not present such othering experiences as relevant to withdrawal (cf. Kewes and Munsch 2019).
}

three specific implicit patterns of orientation, each of which documents the volunteer process: finding a niche, experiencing resonance and voicing protest. All three patterns are presented below; the main focus is on the experiences of resonance and protest, as they result in the specific tensions that shape withdrawal.

\section{Finding a Niche: Roles Defined Through Practice}

The niche-finding frame is based on a recognition that volunteers do not (as sometimes assumed) start volunteering with specific expectations that they then merely attempt to realise (cf. Wilson 2012). True, the interviewees do talk of certain motivations for starting to volunteer, for example that they wanted to test themselves and see what they could still do, or that they were grateful to a particular charity and wanted to give something back. Over the subsequent course of the narratives, however, they make little further (implicit or explicit) reference to those initial motives. For example, when they rate certain moments in their volunteering role as successful or difficult or explain a certain development, they refer to specific experiences that occurred later in their role and not to their initial motivations.

Evaluations of the initial passages in particular show that the volunteers interviewed only gradually sought and found specific tasks in what tended to be the charity's broad field of work once they had started volunteering. The volunteers also recount that they had not expected or could not have pictured certain experiences. It is only through their actual experiences in practice that the volunteers develop a specific concept of what defines their particular work-and most importantly, of what defines them as volunteers. On the basis of those experiences, they can then describe themselves as carrying out their volunteering role particularly well in a way that is specific to them. They draw a distinction between themselves and others whom they see as less committed or as not giving clients the attention they deserve. Such narratives indicate that volunteers do not simply internalise the role requirements of their organisation, as conventional role theory would lead us to expect, but that they develop those requirements further and in turn apply them to others. This is the basis for the development of the emotional forces that are reconstructed in more detail below.

\section{Resonance Strengthens Commitment}

As the interviews were conducted with people who had stopped volunteering and the interviewees were explicitly asked for the story of that withdrawal, one would have expected the reasons for withdrawal to dominate the narratives. However, this was not the case. Our findings in fact 
show that the narratives of most of the volunteers who dropped out centre on particularly good and memorable experiences. The volunteers talk at length about relationships, in particular those with clients or other volunteers. Of particular relevance to the analysis are the complex and detailed descriptions of special moments of intimacy, recognition, sincerity and support that were highlighted by the (former) volunteers, and the findings show that these special moments of resonance are important in giving meaning to a volunteering role-even if the volunteer later withdraws. We term these experiences resonance according to Hartmut Rosa's resonance theory (2016). The term describes experiences that have a particular significance to the volunteers, in a personal as well as volunteering context, and that strengthen volunteers' commitment. An analysis of the interview data reveals three different types of resonance. The following pages reconstruct both the specific and typical aspects of those three types on the basis of passages from the interviews.

\section{Resonance in Work with Clients}

The focus of some volunteer narratives is the special relationships between the volunteers and their clients, and in these narratives, the role of human contact is important. The volunteers stress how their skills helped to build a special relationship, and how this led to a special response to their service.

One such a narrative is from Gül, who has withdrawn from her volunteering role with the elderly. In the interview, she gives one example that was important to her:

Gül: [...] Someone who hadn't laughed since she got ill, her daughter said. [...] So I read through her notes, she was a housewife, had three children and had only ever kept house. She hadn't done anything else. But she liked reading the Koran and singing, but that was never done at home. The woman just sat there all day and night, and then she joined the group. I said to her, "We'll get you laughing". And so first I read a few [...] suras from the Koran. And em her eyes/you can see it, her eyes (smiles) got bigger somehow. And em I saw that something had got through to her, right? with the sura. And then I sang with her. [...] Islamic songs. Illahi songs we call them. [...] You could see she was enjoying it. She even laughed. She got up, she was mobile, yes, by the end she was totally different. Then her daughter came to pick her up and saw her mother was laughing. She was like "I don't believe it". She hadn't done that for, let's say, how long? She'd been ill for 9 months. And for 9 months she hadn't laughed, she said, right? ((laughs)) The first time she'd laughed, eh, because, for the sick, right, you need to know how to make them happy, right? What can make them happy. That's something you need to find out, right? [...] And I won't ever forget it either. That was a success for me too. ${ }^{4}$

Gül recounts this passage initially as a textbook care situation in which strict application of the rule (working on the basis of the client's life story and preferences) actually achieved a response. However, this story is more than just Gül highlighting her skills, and this is made clear at the end when she recounts sharing in the joy of the family and herself experiencing the moment as a success. The emotionality of the passage is highlighted by her laughing as she tells the story; Gül's repeated expression of emotion corresponds in structure to the content of the narrative.

She persistently emphasises human, physical responses: the eyes of the elderly woman, her brightening up, the movement and laughing with the family. What is special about the woman's actions is illustrated by the contrast drawn between her different physical states. By broadening the narrated care situation to include the exchange with the family and by indicating that others also recognise Gül's service, this narrative in our view documents a specific volunteer world that consists of more than the mere processing of tasks. At the centre of the narrative are instead both the successful self-relations that come from feeling good at work and improvements in the quality of life of others. The latter are explicitly mentioned by Gül as an indicator of the quality of her service. This narrative is thus not simply an account of a personal achievement. In fact, the volunteer is drawing attention to an unexpected case of resonance, to which she gives further weight by classifying the event as unforgettable.

A comparison with other interviews reveals a number of similarities: narratives about this type of resonance are notable for their very concrete observation of physical responses by clients to a specific action by the volunteers. The volunteers recount their most important volunteering experiences as moments in which they are touched or affected by and feel an intense connection with those whom they are serving. They outline how their environment - both clients and relatives_responded to them in a positive and affirming way. Such responses appear all the more significant as the narratives here relate to clients from whom they would not, on the grounds of illness or age, necessarily have been expected. The aspect of the inaccessibility of resonance described by Rosa (cf. Rosa 2018, p. 48) clearly emerges here. In our view, this aspect is of considerable importance to volunteering management but has unfortunately yet to be explored in any depth. At the same time, volunteers' actions are recounted as completed acts of creative problem-solving that involve physical, sensory and reflective competencies. As the interviewees present these passages as representative of their

\footnotetext{
${ }^{4}$ Interview with Gül, lines 1144-1201, author's translation.
} 
volunteering experience overall, our interpretation is that the actions recounted are also illustrative of the volunteers' service in the welfare sector.

\section{Resonance in Collective Evaluation}

In the second type of resonance narrative, the focus is on the common evaluation of service or of a particular activity. Resonance can thus also be experienced in the mutual assurance of an activity's meaning or value and is therefore a useful umbrella term for relations experienced by volunteers.

One clear example is in the narrative of İsmail, who has stopped volunteering for a translation and interpreting service.

İsmail: Each year in our town-for a week-we have a big clean-up. [...] the mayor then tries to get everyoneafter the clean-up/we meet up em it's at the central square. And then there's coffee and cake, there are tables and benches, and you sit down together, right? We talk about what we've done/but it's more or less like another thankyou from the mayor to say he's glad that there are people who do things like that. Or when there are other platforms, let's say people who are em active in other ways, the other people/and em then in the city hall ((hesitates)) there's also a stage for all these people you don't always see, but they are there. And on that day, you see them. They are given a platform, and they come up on stage. Maybe not all of them but em, and then you stand there. And you hear all the kind words, the praise, the words that do you good. And then ((claps his hands)) there's this feeling, a great feeling. Because it's harvest day. You are getting the fruits of what you invested for all those months or maybe even years. And this day is pay-day. It's your harvest day, and the harvest comes. ${ }^{5}$

Central to the entire passage are the symbolic moments of thanks and recognition. The setting for the events is recounted in detail, as if it were special and remarkable. We have here a precise observation of speaker roles in public: people who are not actually visible and are therefore hard to address and whose actions and calls for action are almost impossible to see or hear are brought into the public eye, can now be addressed and in turn address the public. İsmail uses positive terms such as pride, happiness, pay-day and harvest day and unambiguous attributes such as good, of praise, that do you good and happy. Volunteering in this case is the starting point for resonance from a population that otherwise remains abstract. That population is not portrayed as indifferent, unlike people who drop litter or dump their waste. In fact, the narrative illustrates a

$\overline{5}$ Interview with İsmail, lines 485-525, author's translation. form of community of values, symbolised by the mayor, that is working towards a common goal.

The significance and focus of the volunteer's account comes from its emphasis on creating visibility and on solidarity between citizens and their political representatives. Ismail observes in symbolic detail the relationship between the individual volunteer and the municipality. We interpret this as a relationship of resonance between the public authorities, other volunteers and İsmail. $\mathrm{He}$ is, as it were, talking about the ritualised creation of community as the moment that makes his relation to the world (in this case his own town) tangible.

A comparison with other interview passages reveals a number of similarities: the emphasis is on a sense of community, which is expressed in the same moral code and judgement. The passages with a high level of metaphor deal with fundamental social issues: processes of recognition are recounted against the backdrop of supposed societal indifference or of exclusion and devaluation. The focus is on the validity of social norms within the group of volunteers, and these norms are presented as key to the volunteers' social definition of themselves. We could say that volunteering provides a context in which resonance is experienced as the affirmation of membership of a community of values. These moments in which the volunteer sees that he or she shares important values with others are highlighted as powerful experiences. Resonance here is less of a physical and more of a cognitive experience, but one that nevertheless affects the volunteer intensely. Resonance was not the planned objective of a given action, but has become important in the course of that action.

\section{An Absence of Resonance}

Finally, there are also volunteering narratives that do not recount powerful experiences of resonance or affirmation, but instead indifference and ineffectiveness in relation to both the activities recounted and experiences within the group. Volunteer experiences are now narrated as negative, but presented as if the volunteers had expected positive experiences. In other words, the volunteers recount their stories as if they were lacking a "responding world".

Natasha reports on her volunteering work in a charity clothes shop.

Natasha: We got the stuff, it was then sorted, and then there was another room where we put the other stuff, the stuff that had to go back, I mean that was to go out. [...] Right at the start, I asked what happened to that stuff. Like I said, no answer. Kept on sorting, right. A few months later I asked again because there was so much stuff. It was/ I reckon it was a few hundred kilos. That's how much got taken away again. I mean sometimes we got maybe twenty bags, and they only kept one bag. The rest went. Em and so 
I kept asking myself what happened to it. And I did a bit of research on the Internet and looked to see what happened to old clothes. And things kept going on like that because I didn't get an answer to my questions, and that bothered me. The way I see it, if someone doesn't give me an answer, that's an answer. ${ }^{6}$

In the passage above, the volunteer complains that her questions were not answered. She sees this in itself as an outrage. An analysis of the passage shows how repeated failure to obtain an answer ultimately undermines the meaning of her service. Natasha asked about the whereabouts of clothes donations that have mysteriously disappeared. However, she was unable to get a response. This raised her suspicions of potential illegitimate actions in which she might indirectly be involved. The passage above illustrates both a need to reassure oneself of the sense and purpose of an activity through communication with others, and a possible conflict between one's actions and one's values.

A comparison of the empirical examples that do not recount resonance reveals similar patterns. For example, the very lack of answers needed to confirm the sense of a volunteering role are a central aspect of the narratives: feedback or positive responses are the implicit backdrop against which their absence is recounted. These narratives repeatedly and clearly show the inaccessibility of resonance. The volunteers in question also speak as if their negative experiences and the non-responding world have redefined their service: Natasha decides to withdraw.

\section{Summary}

Consider the narratives from the resonance angle, and it becomes clear that the volunteers are not primarily arguing in terms of general goals or abstract motives for their volunteering. Instead, what they present as key to the development of a sense of purpose are in fact powerful experiences in the course of volunteering itself: on the one hand, in their relationship with clients, and on the other, in a shared understanding of important events. Commitment is presented as emerging through special and deeply human experiences. We have called these experiences resonance using the terminology defined by Hartmut Rosa (2016). As part of his sociology of the good life, ${ }^{7}$ the sociologist Hartmut Rosa has investigated the requirements and structures for good living. Rosa's resonance theory centres on "being in the world"; on how people synchronise interactions and in so doing create self-world relations in

\footnotetext{
${ }^{6}$ Interview with Natasha, lines 808-829, author's translation.

7 Hartmut Rosa's resonance theory has had an important role in German-language sociology since its extensive elaboration (Rosa 2016).
}

an era shaped by increasing dynamisation and acceleration. Rosa uses a fairly soft vocabulary: he focuses on sense or feeling and on mood, on the physical nature of experience and on "bidirectional vibration"- the last being a feature of resonant relations with the world. Not every relation or "response" leads to resonance, only those in which people feel that the Other in the relationship is of relevance to their own self and where powerful values are involved (Rosa 2018 , p. 48). One central experience here is that of being touched or affected (ibid.). Resonance according to Rosa is a special, inaccessible moment - if it could be planned or were too frequent, this would destroy the resonance experience (ibid.). This becomes clear in our findings, for the volunteers tend to recount such experiences in a tone of surprise - and not as if they were the realisation of a hope or expectation. Resonance theory thus offers us a view of volunteers as resonance-sensitive subjects-but not as explicitly seeking or indeed as optimising resonance. The particularly close human contact that characterises care relationships, strong value judgements and emotional experiences plays a key role here. Moreover, the focus on resonance is extremely useful in a procedural approach to volunteering as it offers a way of understanding the nonlinear development of volunteer motivations, motivations which in precisely these special moments have their very own dynamics.

\section{Protest}

To understand why volunteers who have experienced such strong resonance nevertheless drop out of volunteering, we first need to understand the narratives of protest. Dropouts recount their service both as a positive experience and at the same time as a source of vexation. The simultaneity of these conflicting experiences is a key finding of our project: for volunteers, volunteering clearly has not just one but in fact many different meanings, which can be at odds with each other (cf. Eliasoph 2016). The following reconstructions may also offer an explanation for the unexpected findings by Stukas et al. (2009, p. 22), who noted with surprise that it was in fact the most motivated volunteers who experienced their volunteering as "somewhat more emotionally draining, frustrating, and disappointing".

Many volunteers voice protest against what they see in their service. Protests can, for example, be directed against the morality of a task or the moral shortcomings of the organisation: you cannot, the volunteers argue, treat people in the way that the organisation does or is demanding that they do. The example of Natasha cited above is one such a protest. Natasha withdraws on the grounds that she cannot continue to accept the lack of transparency surrounding the clothes donations. In other narratives, protest is directed against medication in care homes, for example. Another 
volunteer is distressed to observe that elderly people are perceived simply as "non-private patients", in other words considered only in terms of income and expenditure, and not as "(fellow) residents". Both volunteers had previously recounted positive relations, in particular with clients. Other volunteers protest at how colleagues or paid staff failed to recognise or appreciate their skills.

Before we can understand the dynamics of withdrawal processes, we need not to ask whether protest is subjectively justified but to reconstruct its specific dynamics from the perspective of the volunteers.

\section{The Development of Protest Through Specific Experiences}

An analysis of protest in the sequential narratives clearly shows that the volunteers do not introduce themselves as critical subjects per se. They do not start volunteering in the welfare sector with the aim of combating injustices or abuses, as one might expect from other forms of participation (for example, in political movements). Instead, protest only develops over the course of volunteering itself, after they have found specific tasks and built up genuine relationships within the field in which they are working.

The narratives reveal a specific link between actual experiences and generalisations on the basis of those experiences. One example of such experiences is in the narrative of the volunteer Linda on her work in a care home.

The volunteer recounts an incident with an incomplete wheelchair as typical. She had simply taken the wheelchair she was given, which had no footrests, without thinking about the fact that the elderly lady she was looking after would have to hold up her feet. As Linda then noticed the pain the lady was suffering, she asked why the home kept wheelchairs that were missing parts. The paid member of staff had dismissed her question as if the opinion of a volunteer did not count. However, as not only her proposed improvement but also the pain suffered by the elderly lady had apparently been dismissed as irrelevant, the volunteer started to wonder how else the home might be disrespecting the residents' rights. Then, Linda recounts, she noticed that staff were too quick to medicate the elderly residents. Linda argues that it is perfectly possible for the elderly people to be "healthily tired out", 8 but this demanded time and a sensitivity that was not forthcoming from anyone in the home.

A comparison with other interviews reveals that both the structure of the passage and the content of the narrative are typical: protest does not appear at the start of the narrative; it emerges as a result of actual experiences. Those experiences are presented as representative of problems or

8 Interview with Linda, lines 472-473, author's translation. injustices encountered, and their detailed description, the passion with which they are recounted, and their weight in the interview give them a particular significance. The volunteers see the episodes in question as challenging their very principles, and the narratives place the volunteers in opposition to what they are experiencing in their volunteering. Linda seeks to show the interviewer just how far her position as a volunteer is from the position of the care home provider. Her protest is directed at more general social circumstances rather than first and foremost at specific people or institutions.

A comparison of the various interviews reveals other aspects that are typical of the protest experiences recounted. These are presented below.

\section{Emotionality}

Strong emotions run through Linda's account of her protest at what she experienced in the care home, above all outrage but also sympathy with the residents and pain at what she was seeing. A comparison of the accounts of protests shows that the interviewees recount emotions in very different ways. Some interviewees become very emotional. Others simply use a very strong mode of expression in certain individual passages, which we interpret as evidence that the situation they are describing provoked strong emotions. Yet across all the different narrative styles, experiences of protests always seem to touch the emotions of the volunteers.

Our assumption here is as follows: the volunteers have not merely seen issues and mention these in rational terms in the course of the interview, and for the purposes of our analysis, we need to explore the emotionality in the individual narratives. That emotionality can be interpreted as an indication of a crisis or turning point: at such points, the volunteers are apparently faced with being unable to continue with what they had found to be an acceptable or successful routine. We read in their accounts that what they have seen prevents them from simply carrying on as before. Clearly, it is not only volunteers' own motivation that is being called into question here and they are not uncertain about their own roles or duties, as volunteering researchers have previously suggested. Fundamental convictions are also in question.

We argue that emotion in accounts of protest is also connected to previous accounts by the same volunteers of very positive experiences that created a bond with their clients or cemented a specific understanding of their work and their role. We think that volunteers will be particularly affected by the fate of people to whom they have developed close human contact. This applies in particular if the volunteers believe those people are being dealt with unfairly or inhumanely. 


\section{Solitary Protest, Rarely Articulated}

As emotional as the interviewees are as they express their protest to the interviewer, there is little mention of specific actions such as suggesting improvements, voicing criticism or otherwise clearly articulating their protest within the relevant institutions. Some volunteers do not even explicitly voice their protest to the competent parties, for example the social work professional responsible for the volunteers. They may think about talking to the institution management, but ultimately do not. Only a few report that they did discuss their concerns with the competent people; this was then not successful. ${ }^{9}$ One volunteer recounts that other staff advised her against such a move, because there was no point-"Don't bother yourself". ${ }^{10}$ Our field contacts complained during our preparation phase, as did many of the paid staff from the charities when we subsequently presented our findings, that they seldom heard about discontent amongst the volunteers because the issues were rarely raised; exit was preferred to protest, and the potential critical input was lost to the organisation. Another interesting point here is that some volunteers recount having discussed their volunteering with their partner, friends or others close to them. It may have made more sense to them to share their protest with someone close to them, someone with whom they had certain values in common, than with an organisation that they did not expect to share those values. Indeed, rarely do the interviews mention successful changes.

The absence of an explicit protest can be put down firstly to the specific social context of that protest: we observed that volunteers presented their protest as a solitary act. This is also clear in the interview with Linda: her account of her outrage, of her complaining to the competent member of staff and of her ultimately mulling over her discontent at home portrays her as a lone individual. At no point does she mention other volunteers (or members of staff) offering any form of support. A comparison of the various narratives reveals that this is typical.

Our material does not allow us to reach any clear conclusion on the reasons for this approach. Some volunteers recount that they did not see fellow volunteers as able to voice protest or implement improvements because they were too old, too uncritical or were too bound up in their work. Others, throughout the entire interview, portrayed themselves as lone warriors who largely carried out their service on their own. Similarly, proposed improvements did not seem to be widely articulated in the field either, on

\footnotetext{
9 On the basis of their own empirical findings, Allen and Mueller (2013) also argue that criticism not being taken seriously can be a possible reason for withdrawal.

${ }^{10}$ Interview with Natasha, lines 1419-1420, author's translation.
}

the contrary: not only do the volunteers appear more or less alone with the clients in the context of their service, they also appear isolated in their protest. Protest is thus not recounted as the starting point for a coalition, for example with other volunteers or with paid staff. The lack of other people with whom to interact may explain why the former volunteers we interviewed did not remain in their role and initiate further protest.

\section{Vague Addressees}

We need to distinguish between the social context of a protest and the question of whether it in fact occurs, and the parties mentioned in the narratives as the possible addressees of that protest. Often, the interviewees are unsure of whom to approach because the group of potential contact people either is too vague or does not appear competent. This is also clear from an analysis of Linda's narrative. In her interview, she says that the home itself cannot define the services it offers, as it is reliant on funding from institutions further up the hierarchy ("I mean, it's not the home's fault. Because they get told how many people they can employ."11). The alternative scenario to such a situation is a home that does have the power to decide on its own personnel. In such a home, the management could be approached and usefully criticised. Linda's qualification indicates that she is indeed thinking about responsibility when she voices her criticism-but does not accept that her direct contact person has that responsibility.

A comparison of the interviews reveals typical features in the possible direction of protest. The narratives repeatedly mention specific contact people, but ultimately do not define those people as responsible for the areas in need of improvement. This means criticism is often directed at faceless, abstract and impersonal structures, organisations, processes, etc. Specific players are represented as simply small cogs in the machine and described in most interviews in brief and impersonal terms: the nun in the care home, the office worker in the charity's regional office, etc. As they are not credited with being responsible for or able to discuss a given practice, they are not considered as potential addressees for protest. Certain volunteers stress quite explicitly that their protest is not directed at a specific institution, but at a fairly widespread situation. If criticism and proposals for improvement are to be explicitly voiced, the volunteers must believe that the staff in question could actually make a difference-and in the case of welfare charities in Germany, which are, for example, reliant on rates negotiated with the health insurers, this apparently tends not to be the case.

\footnotetext{
${ }^{11}$ Interview with Linda, lines 460-462, author's translation.
} 


\section{Protest as Positioning Beyond the End of Service}

An analysis of the narratives clearly shows that protest can also be a form of positioning that lasts well beyond the end of service. In other words, the volunteers present themselves as politically or morally committed even after withdrawing by attributing to their place of work or organisation characteristics that they describe as contrary to their personal principles. We use positioning in the sense defined by Lucius-Hoene and Deppermann as "discursive practices that people use in verbal interactions to create and present their persona and the personae of others in relation to one other, and what attributes, roles, characteristics and motives they adopt themselves and attribute to others through their actions" $(2004$, p. 168). In and through their narratives, the volunteers position themselves in relation to their area of volunteering and its key players. Self-positioning therefore always also involves other-positioning. By positioning themselves in relation to specific values or tasks and defining the charities in terms of values or tasks that are contrary to and not compatible with their own, the volunteers point to possible alternative courses of action. The narratives thus reproduce tensions by indicating that tasks can be carried out or indeed justified in very different ways. Take, for example, the volunteer cited above: surely no one would disagree with her call for greater care in the provision of wheelchairs. However, representatives of the relevant charities in particular would point out that continuous inspection of all items used in care would occupy far too much time. We would postulate that this tension is typical within the welfare sector, which has to organise help at the interface of efficiency and humanity. ${ }^{12}$ We think of protest in this sense as the expression of a knowledge that develops through powerful volunteering experiences and that remains after the end of that volunteering role. The positioning of the charities and their players as recounted, and the self-positioning of the volunteers through their profession of specific ideals and values, appear to us to be so important that they will continue to apply beyond the end of a volunteer's service. Self-positioning in opposition to the volunteering field does not, however, mean that the volunteers will never volunteer again. It merely precludes service in the particular conditions criticised.

\section{Summary: Protest as Positioning}

Protest as positioning develops on the basis of powerful experiences, which feed into generalisations by the volunteers. Volunteers speak with emotion, which indicates

\footnotetext{
12 This approach is, however, already established and has been widely discussed. cf. Haubner (2017) or Browne (2010), both of whom also raise this conflict.
}

that the circumstances they are criticising run contrary to fundamental convictions. However, the volunteers recognise that what they are protesting about is not limited to a specific institution, and certainly not to individual members of staff or managers. People and events tend to appear in the narratives as examples of more general issues. In such a context, the target of the protest is unclear. In some cases, the volunteers define the breach of their fundamental values as taking place on such an abstract systemic level that there is little scope for practical improvement. The lack of both specific addressees and fellow protesters means that protest does not lead to explicit action. This takes us finally to the concept of protest as positioning. The term protest appears appropriate to us as the volunteers are vehemently arguing against something which they do not wish to support in its current form. Unlike a collective protest movement, which seeks to bring about change, the protest reconstructed here remains an individual position. Although in some cases it is recounted with great emotional power, its addressees are limited to the interviewer and friends or partners, in other words to the non-public sphere. $^{13}$

\section{Should I Stay or Should I Go? Between Resonance and Protest}

Understanding the experiences outlined, both of resonance and of protest, is central to capturing the dynamics of withdrawal. Withdrawal can only be recounted and understood in the context of a specific volunteering experience. Specific, socialised volunteers drop out of specific volunteering roles that have become important to them. For the narratives on withdrawal, we reconstructed the interaction or tension between the two aspects, resonance and protest. The narratives demonstrate that an inner conflict is typical of withdrawal processes. On the one hand, there are powerful experiences that strengthen the volunteer's commitment - and on the other, experiences that contribute to volunteers no longer being willing or able to support what they see in the institutions. This conflict often occupies the volunteers for a considerable time. Examples here include long discussions in which they and their partner or other people important to them weigh up the arguments for and against their service. Not all narratives are marked by serious struggles or strong emotions. It is nonetheless clear in all cases that withdrawal is shaped by a tension or conflict that could not be quickly or easily resolved. In our study, the typical withdrawal from a long-term volunteering role in the welfare sector is thus not primarily the result

\footnotetext{
13 This distinguishes the protest as positioning reconstructed here from the concept of voice as described by Hirschman (1970).
} 
of a rationally considered decision, nor is it sudden or rapid.

It was also clear that the volunteers interviewed in the group discussions, who had not dropped out, also experienced those tensions but dealt with them differently: the patterns of orientation for resonance and protest and thus also the tensions outlined appear less extreme in the group discussions. The fact that the resonance narratives are more moderate can be put down to the empirical method used, as group discussions provide less scope for individual accounts. In terms of protest, groups of volunteers who do not withdraw also position themselves in opposition to approaches or methods that they observe in their institution or tasks that they are to carry out. However, a different habitus emerges in their narratives: they treat the problem as an irritating or unfortunate circumstance but one which they are not allowing to get them down.

Alongside these two types of great tension between resonance and protest on the one hand and the less pronounced tension in the case of non-dropouts, there is also a third type of withdrawal, in which there is no protest. We see this as the result of a lack of commitment that means that volunteers are not touched or affected by their work. ${ }^{14}$

\section{The Volunteering Context: Welfare Charities}

If we look for the central, common experiences underlying the reconstructed patterns of orientation of resonance and protest, we can see that those experiences are specific to the welfare context. The first element that is key to resonance experiences is the specific type of relationship in care between helpers and the clients, who are often ill, elderly or otherwise in need and who respond to help in a specific way. Beaming smiles enthusiastically recounted in the narratives are representative of that response. At the heart of this experience is first and foremost the fieldspecific distinction between the narrators as those able to help others, and the others who need that help. Another central aspect is the close human contact often involved in care relationships, which can lead to a particular intimacy.

Research into social care and welfare charities reveals fundamental conditions in this field that also shape the experiences of resonance and protest outlined. Two of the aspects highlighted in the analysis of social care by Daly and Lewis (2000) appear to us to be fundamental to an understanding of resonance experiences: social care has historically primarily been provided by women and has

\footnotetext{
14 Withdrawal on the grounds of a lack of time or a change of address was cited twice in our sample. While these cases may be highly significant in statistical terms, their interpretation would appear of secondary importance in establishing the subjective sense of volunteering.
}

gone and still does go largely unrecognised by society as a whole. Work in this sector is often unnoticed or unappreciated. We argue that this is one important reason why volunteers highlight the recognition and appreciation of their work as such a special moment. Social care also refers to a moral interrelationship of duties and responsibilities (cf. ibid.). This focus on values and morality is important to understanding the significance to volunteers of a collective assurance and affirmation of those values.

Even the pattern of orientation of protest is shaped by a feature specific to social care: it transcends the boundary between the private and the public (this is the third dimension of social care according to Daly and Lewis 2000). The organisation and funding of care work in Germany and elsewhere is increasingly being taken out of public-sector control and moved to the private sector (cf. Bode 2011). This means on the one hand that there are care markets and these have an impact on the approach to care and how it is provided. On the other, the reduction in key areas of life to mere services is increasingly the object of (moral) judgement, criticism and protest, not least because care for the elderly, the marginalised and victims of violence has such strong moral implications. The distinction drawn by the volunteers interviewed between human care and mere mechanical service provision by paid staff or through care provision structures is evidence of criticism, typical for this field, of the focus on efficiency or of the economisation and industrialisation of care (cf. Liebig 2011 for Germany). As experiences in the welfare sector have such an important role in shaping the dynamics of the volunteer process in our study, we would recommend that future research distinguish much more between the different volunteering fields in any analysis of motivations, intentions to remain and withdrawal (for a similar idea, but with alternative methods and terms, see: Lichterman and Eliasoph 2014; Maki and Snyder 2016; Smith and van Puyvelde 2016).

\section{Conclusions}

There are four ways in which the findings presented help to develop the understanding of processuality in volunteering research and theory. Firstly, one key finding of our research is that the meaning that engenders volunteer commitment develops progressively through actual experiences in practice. Although the volunteers mention motives that led them to start volunteering, they make little further reference to those motives in their subsequent narratives. It is instead powerful volunteer experiences in the course of their volunteering that are central to understanding the dynamics of that volunteering (cf. Yanay and Yanay (2008). An analysis of how the volunteers give their service 
a positive sense (building commitment) and a negative sense (potentially leading to withdrawal) clearly shows the relevance of specific experiences to the volunteers. Their narrative style gives these experiences a defined social meaning (for example, particularly positive or degrading). This puts into perspective the significance of a "before" like that described by Snyder and Omoto (2008), for example, for the volunteer process.

It is also clear that the process is not, from the volunteers' perspective, an ordered sequence of steps or levels like that described by Chacón et al. (2007). In fact, in the narratives we have reconstructed, engaging and disengaging factors apply simultaneously. These factors and the tension between them appear to intensify over the course of service.

Thirdly, our findings deepen a specific understanding of volunteers. They show that whether or not and how the volunteers engage with their service, in other words with their tasks and indeed also with general attitudes in the field, shapes the dynamics of the volunteer process. For the reconstruction of narratives, both on resonance and on protest show that volunteers do not simply take on tasks without question or without thought. In fact, they develop their own meaning with the tensions that it involves in the context and course of service. Key to that development is that volunteers are sensitive to feedback on their work and to moral practice in their volunteering environment. Volunteers seek and find specific activities that they undertake in a specific way, and to which they lend a specific importance. They engage critically with the prevailing conditions, observe those conditions and gradually develop their own position as distinct from the field of volunteering. That position remains even after their departure and is expressed in their narratives. Our selected research method thus allows us to understand volunteers as "eigensinnige" subjects who assign their experiences a meaning - and in so doing shape the dynamics of their volunteering. This is in line with studies that describe volunteers as particularly interested in the meaningfulness of their actions and their life (cf. Schnell and Hoof 2012). It also ties in with the (German language) discourse on "Eigensinn" as a central feature of volunteering. As used by German-speaking authors in this field, "Eigensinn" is an aspect specific to volunteering that follows its own logic, that of free choice and cannot be reduced to social functions (Enquete-Kommission 2002: p. 89). It is argued that "eigensinniges" service is important in providing "a critical outside perspective and for the development of the organisation" (Backhaus-Maul et al. 2015: p. 194).

Fourthly, on the basis of our findings, we suggest that future research understands and explores volunteering dynamics in connection with field logics and imperatives. The emotional forces that develop or strengthen volunteer commitment or lead to withdrawal are clearly shaped by the field in which the volunteer is operating. One defining feature of the welfare sector is the close human contact typical of care. That intimacy can allow the experiences of resonance recounted in the narratives. Another central aspect of the welfare sector is economisation, and this is criticised by the volunteers in their protests. The tensions between resonance and protest that clearly emerge in the narratives are thus, in the welfare sector, a product of the conflict between very human care relations on the one hand and the economisation and efficiency drive in the sector on the other. We therefore conclude that the focus should be different from that defined by Haski-Leventhal and Bargal (2008): our findings suggest that it is the field-specific logic and imperatives rather than the relationship between volunteer and organisation that are most important in shaping volunteering dynamics. Whether those logics and imperatives in other fields are similar to or entirely different from those in the welfare sector is a question for further research. Such an explanation of volunteering in terms of the specific sector also opens up a new perspective, and one that is relatively unusual: the dominant explanation of volunteering has to date used individual features and motives (cf. Simonson et al. 2017; Wilson 2012).

Finally, what insights can we offer for volunteering management? Certain interviewees questioned us closely on whether our research was aimed at helping the management responsible for volunteers in the organisations. They were greatly relieved to hear that such practical advice was not the objective of our research. Nonetheless, our findings pose fundamental questions for the promotion and development of volunteering: if resonance by its nature is fleeting and cannot be planned, this means first that promotional campaigns or material should be wary of overconfident promises that volunteering will be rewarding or will achieve something for society. Such promises can lead to disappointment. Yet this also means that matching interests, the approach taken in many volunteering organisations, cannot provide any guarantee of volunteer satisfaction in the long term. Another point is this: if volunteers critically engage with their volunteering environment in such depth and detail, do volunteers not then require ongoing support from someone who accepts and responds to that depth of engagement and the intensity of the tensions outlined, and may even be critical of the organisation? Our findings do not show that the volunteers interviewed (who had dropped out) had been taken seriously as partners in such a discussion. Perhaps such a respect for the volunteers' experiences would be one way of not only reducing dropout but also improving the quality of welfare organisations. 
Acknowledgements The paper is based on the research project "Withdrawing from volunteering" conducted by the University of Siegen. We would like to thank the Deutsche Forschungsgemeinschaft for funding the project. Our warm thanks also go to AnneMarie Stumpf, Moritz Müller and Annette Langeheinecke-Utsch for their invaluable help with research.

Funding This study was funded by the German Research Foundation (DFG), Grant Number MU 3635/1-1.

\section{Compliance with Ethical Standards}

Conflict of interest The authors declare that they have no conflict of interest.

Open Access This article is distributed under the terms of the Creative Commons Attribution 4.0 International License (http://crea tivecommons.org/licenses/by/4.0/), which permits unrestricted use, distribution, and reproduction in any medium, provided you give appropriate credit to the original author(s) and the source, provide a link to the Creative Commons license, and indicate if changes were made.

\section{References}

Alfes, K., Shantz, A., \& Saksida, T. (2015). Committed to whom? Unraveling how relational job design influences volunteers' turnover intentions and time spent volunteering. VOLUNTAS: International Journal of Voluntary and Nonprofit Organizations, 26(6), 2479-2499. https://doi.org/10.1007/s11266-014-9526-2.

Allen, J. A., \& Mueller, S. L. (2013). The revolving door. A closer look at major factors in volunteers' intention to quit. Journal of Community Psychology, 41(2), 139-155. https://doi.org/10.1002/ jcop.21519.

Backhaus-Maul, H., Speck, K., Hörnlein, M., \& Krohn, M. (2015). Engagement in der Freien Wohlfahrtspflege. Empirische Befunde aus der Terra incognita eines Spitzenverbandes. Wiesbaden: Springer.

Bode, I. (2011). Creeping marketization and post-corporatist governance. The transformation of state-nonprofit relations in continental Europe. In S. D. Phillips \& S. Rathgeb Smith (Eds.), Governance and regulation in the third sector. International perspectives (pp. 115-141). London: Routledge.

Browne, P. L. (2010). The dialectics of health and social care. Toward a conceptual framework. Theory and Society, 39(5), 575-591. https://doi.org/10.1007/s11186-010-9120-6.

Chacón, F., Vecina, M. L., \& Dávila, M. C. (2007). The three-stage model of volunteers' duration of service. Social Behavior and Personality, 35(5), 627-642. https://doi.org/10.2224/sbp.2007. 35.5.627.

Corrigall-Brown, C. (2012). From the balconies to the barricades, and back? Trajectories of participation in contentious politics. Journal of Civil Society, 8(1), 17-38. https://doi.org/10.1080/ 17448689.2012 .665650

Daly, M., \& Lewis, J. (2000). The concept of social care and the analysis of contemporary welfare states. British Journal of Sociology, 51(2), 281-298. https://doi.org/10.1080/ 00071310050030181

Dury, S. (2018). Dynamics in motivations and reasons to quit in a Care Bank. A qualitative study in Belgium. European Journal of Ageing. https://doi.org/10.1007/s10433-017-0455-y.

Eliasoph, N. (2016). The mantra of empowerment talk. An essay. Journal of Civil Society, 12(3), 247-265. https://doi.org/10.1080/ 17448689.2016.1215895.
Enquete-Kommission "Zukunft des Bürgerschaftlichen Engagements" Deutscher Bundestag (Ed.). (2002). Bürgerschaftliches Engagement: auf dem Weg in eine zukunftsfähige Bürgergesellschaft. Wiesbaden: VS Verlag für Sozialwissenschaften.

Haski-Leventhal, D., \& Bargal, D. (2008). The volunteer stages and transitions model. Organizational socialization of volunteers. Human Relations, 61(1), 67-102. https://doi.org/10.1177/ 0018726707085946.

Haubner, T. (2017). Die Ausbeutung der sorgenden Gemeinschaft. Laienpflege in Deutschland. Frankfurt: Campus.

Hirschman, A. (1970). Exit, voice and loyalty. Cambridge: Harvard University Press.

Hustinx, L., Cnaan, R. A., \& Handy, F. (2010). Navigating theories of volunteering: A hybrid map for a complex phenomenon. Journal for the Theory of Social Behaviour, 40(4), 410-434.

Kewes, A., \& Munsch, C. (2019). Engagementabbrüche in Wohlfahrtsverbänden: Welche Rolle spielt ein „Migrationshintergrund"? In T. Hilse-Carstensen, S. Meusel \& G. Zimmermann (Eds.), Freiwilliges Engagement und soziale Inklusion (pp. 27-40). Wiesbaden: Springer VS. https://doi.org/10.1007/978-3658-23672-4_2

Lichterman, P., \& Eliasoph, N. (2014). Civic action. American Journal of Sociology, 120(3), 798-863. https://doi.org/10.1086/ 679189.

Liebig, R. (2011). Was bleibt für das Ehrenamt? Analysen und Forschungsbefunde zum Wandel der Führungsstrukturen im Sozialbereich. In T. Rauschenbach \& A. Zimmer (Eds.), Bürgerschaftliches Engagement unter Druck? Analysen und Befunde aus den Bereichen Soziales, Kultur und Sport (pp. 29-163). Barbara Budrich: Opladen.

Lucius-Hoene, G., \& Deppermann, A. (2004). Narrative Identität und Positionierung. Gesprächsforschung, 5, 166-183.

Maki, A., \& Snyder, M. (2016). Investigating similarities and differences between volunteer behaviors. Nonprofit and Voluntary Sector Quarterly, 46(1), 5-28. https://doi.org/10.1177/ 0899764015619703.

McAllum, K. (2018). Committing to refugee resettlement volunteering. Attaching, detaching and displacing organizational ties. Human Relations, 71(7), 951-972. https://doi.org/10.1177/ 0018726717729209.

Nohl, A.-M. (2010). Narrative interview and documentary interpretation. In R. Bohnsack, N. Pfaff, \& W. Weller (Eds.), Qualitative analysis and documentary method in international educational research (pp. 195-217). Opladen: Barbara Budrich.

Nohl, A.-M. (2012). Interview und dokumentarische Methode. Anleitungen für die Forschungspraxis (4th ed.). Wiesbaden: Springer.

Omoto, A. M., \& Snyder, M. (1995). Sustained helping without obligation. Motivation, longevity of service, and perceived attitude change among AIDS volunteers. Journal of Personality and Social Psychology, 68(4), 671-686.

O’Toole, M., \& Grey, C. (2015). Beyond choice. 'Thick volunteering and the case of the Royal National Lifeboat Institution. Human Relations, 69(1), 85-109. https://doi.org/10.1177/ 0018726715580156.

Rosa, H. (2016). Resonanz. Eine Soziologie der Weltbeziehung. Berlin: Suhrkamp.

Rosa, H. (2018). Available, accessible, attainable. The mindset of growth and the resonance conception of the good life. In H. Rosa \& C. Henning (Eds.), The good life beyond growth. New perspectives (pp. 39-53). London, New York: Routledge.

Schnell, T., \& Hoof, M. (2012). Meaningful commitment. Finding meaning in volunteer work. Journal of Beliefs \& Values, 33(1), 35-53. https://doi.org/10.1080/13617672.2012.650029. 
Simonson, J., Vogel, C., \& Tesch-Römer, C. (2017). Freiwilliges Engagement in Deutschland. Der Deutsche Freiwilligensurvey 2014. Wiesbaden: Springer.

Smith, D. H., \& van Puyvelde, S. (2016). Theories of associations and volunteering. In D. H. Smith, R. A. Stebbins, \& J. Grotz (Eds.), The Palgrave handbook of volunteering, civic participation, and nonprofit associations (Vol. 1, pp. 59-89). New York, NY: Palgrave Macmillan.

Snyder, M., \& Omoto, A. M. (2008). Volunteerism: Social issues perspectives and social policy implications. Social Issues and Policy Review, 2(1), 1-36.

Stukas, A. A., Worth, K. A., Clary, E. G., \& Snyder, M. (2009). The matching of motivations to affordances in the volunteer environment. Nonprofit and Voluntary Sector Quarterly, 38(1), 5-28. https://doi.org/10.1177/0899764008314810.
Willems, J., Huybrechts, G., Jegers, M., Vantilborgh, T., Bidee, J., \& Pepermans, R. (2012). Volunteer decisions (not) to leave. Reasons to quit versus functional motives to stay. Human Relations, 65(7), 883-900. https://doi.org/10.1177/ 0018726712442554.

Wilson, J. (2012). Volunteerism research. A review essay. Nonprofit and Voluntary Sector Quarterly, 41(2), 176-212. https://doi.org/ $10.1177 / 0899764011434558$.

Yanay, G. V., \& Yanay, N. (2008). The decline of motivation? From commitment to dropping out of volunteering. Nonprofit Management Leadership, 19(1), 65-78. https://doi.org/10.1002/nml. 205.

Publisher's Note Springer Nature remains neutral with regard to jurisdictional claims in published maps and institutional affiliations. 